\title{
VviRafS5 Is a Raffinose Synthase Involved in Cold Acclimation in Grapevine Woody Tissues
}

\author{
Henrique Noronha ${ }^{1,2 *}$, Angélica Silva ${ }^{1,2}$, Tiago Silva $^{1}$, Sarah Frusciante ${ }^{3}$, \\ Gianfranco Diretto ${ }^{3}$ and Hernâni Gerós ${ }^{1,2,4}$
}

'Department of Biology, Centre of Molecular and Environmental Biology (CBMA), University of Minho, Braga, Portugal, ${ }^{2}$ Centre for the Research and Technology of Agro-Environmental and Biological Sciences (CITAB), University of Trás-os-Montes e Alto Douro, Vila Real, Portugal, ${ }^{3}$ Casaccia Research Center, ENEA, Italian National Agency for New Technologies, Energy and Sustainable Economic Development, Rome, Italy, ${ }^{4}$ Department of Engineering, Centre of Biological Engineering (CEB), University of Minho, Braga, Portugal

\section{OPEN ACCESS}

Edited by:

Santiago Signorelli,

Universidad de la República, Uruguay

Reviewed by:

Shaun Peters,

Stellenbosch University, South Africa

Henry Christopher Janse van

Rensburg,

University of Basel, Switzerland

Łukasz Pawet Tarkowski,

INRA Centre Angers-Nantes Pays de

la Loire, France

*Correspondence:

Henrique Noronha

henriquenoronha@bio.uminho.pt

Specialty section:

This article was submitted to Plant Physiology

a section of the journal

Frontiers in Plant Science

Received: 06 August 2021

Accepted: 31 December 2021

Published: 15 February 2022

Citation:

Noronha $H$, Silva A, Silva T,

Frusciante $S$, Diretto $G$ and

Gerós H (2022) VviRafS5 Is a

Raffinose Synthase Involved in Cold

Acclimation in Grapevine Woody

Tissues.

Front. Plant Sci. 12:754537.

doi: 10.3389/fp/s.2021.754537
The accumulation of raffinose family oligosaccharides (RFOs) is a hallmark of plant response to different abiotic stresses, including cold. The synthesis of galactinol, by galactinol synthases (GolS), and raffinose, by raffinose synthases (RafS), are fundamental for stress-induced accumulation of RFOs, but the role of these enzymes in the cold response of grapevine (Vitis vinifera L.) woody tissues is still unclear. To address this gap in the literature, 1-year-lignified grapevine canes were incubated at $4^{\circ} \mathrm{C}$ for 7 and 14 days and tissues were analyzed for sugar content and gene expression. Results showed that, in parallel to starch breakdown, there was an increase in soluble sugars, including sucrose, glucose, fructose, raffinose, and stachyose. Remarkably, abscisic acid (ABA) levels increased during cold acclimation, which correlated with the increased expression of the key ABA-synthesis genes VviNCED2 and VviNCED3. Expression analysis of the VviGolS and $V$ viRafS family allowed the identification of $V$ viRafS5 as a key player in grapevine cold response. The overexpression of VviRafS5 in Saccharomyces cerevisiae allowed the biochemical characterization of the encoded protein as a raffinose synthase with a size of $\sim 87 \mathrm{kDa}$. In grapevine cultured cells, VviRafS5 was upregulated by cold and ABA but not by heat and salt stresses. Our results suggest that ABA accumulation in woody tissues during cold acclimation upregulates VivRafS5 leading to raffinose synthesis.

Keywords: Vitis vinifera, raffinose biosynthesis, RFOs sugars, cold acclimation, woody tissues

\section{INTRODUCTION}

Among different environmental conditions, low temperature $\left(0-15^{\circ} \mathrm{C}\right)$ is the one that mostly affects the geographic distribution of plants, productivity, and yield quality (Thomashow, 1999; Yamaguchi-Shinozaki and Shinozaki, 2006). This is the case of grapevine (Vitis vinifera L.) that grows primarily in temperate and subtropical regions, whose productivity may be severely affected by environmental fluctuations (Bock et al., 2013). In particular, cold stress, such as rapid temperature drop in late fall, freezing temperatures in midwinter, or early spring frost, can seriously damage grapevines by reducing their growth and photosynthesis, retarding flowering, 
and compromising fruit production (Fennell, 2004; Hendrickson et al., 2004; Ait Barka et al., 2006; Xin et al., 2013). Also, when exposed to harsh winters, grapevine may suffer from delayed and unsynchronized budbreak, dieback of perennial organs, or even plant death (Antivilo et al., 2020).

Cold acclimation is a physiological process leading to freezing tolerance in plants, which is critical for their ability to withstand harsh winter conditions (Thomashow, 1999; Theocharis et al., 2012). A set of biochemical and molecular adjustments contribute to the plant's adaptation during cold stress, including reduced water uptake, accumulation of cytosolic $\mathrm{Ca}^{2+}$, increased levels of Reactive Oxygen Species (ROS) and the activation of ROS scavenging systems, induction of cold-specific genes (e.g., CBF, C-repeat Binding Factor and ICE genes, Inducer of CBF Expression) and synthesis of cold-related proteins (e.g., CSDPs, cold shock domain proteins), and accumulation of abscisic acid (ABA) and osmolytes (Thomashow, 1999; Mahajan and Tuteja, 2005; Theocharis et al., 2012). Among these, sugar accumulation is one of the most documented plant responses to low temperature (Kaplan et al., 2004; Dietze et al., 2014). In particular, the accumulation of raffinose family oligosaccharides (RFOs), which are $\alpha$-1,6-galactosyl extensions of sucrose (Supplementary Figure 1), is fundamental during cold hardiness (Grant et al., 2009; Egert et al., 2013). Although the protective role of RFOs still remains unclear, they have been associated with the scavenging of ROS, as functioning as osmoprotectants, stabilizing biological membranes, and protection of photosystem II (Taji et al., 2002; Li et al., 2020).

The first step in RFOs formation is catalyzed by galactinol synthase (GolS, EC 2.4.1.123), which forms galactinol from myo-inositol and UDP-galactose. Subsequently, raffinose synthase (RafS; EC 2.4.1.82) catalyzes the synthesis of raffinose by transferring the galactosyl unit from galactinol to sucrose, yielding a trisaccharide (sucrose-galactose). In some species, further elongations may be catalyzed by galactan:galactan galactosyl transferases (GGTs) yielding stachyose (tetrasaccharide) and verbascose (pentasaccharide; Supplementary Figure 1; Peterbauer et al., 2002; Egert et al., 2013; Sengupta et al., 2015).

GolS is considered a key regulator of RFO synthesis and accumulation (Vinson et al., 2020), and the overexpression of two wheat Gols (TaGols1 and TaGols2) in rice promotes the accumulation of galactinol and raffinose and increased coldstress tolerance (Shimozaka and Ozawa, 2015). Also, the expression of a Gols from the desert plant Ammopiptanthus nanus (AnGols1) in tomato improved its tolerance to cold stress (Liu et al., 2020). Interestingly, it has been shown that the Vitis amurensis AQUILO transcription factor improves cold response of Arabidopsis thaliana transgenic plants by regulating AtGolS1/3 and AtRafS5 and increasing RFO content (Sun et al., 2018). Recently, ZmRAFS has been associated with increased plant tolerance to drought ( $\mathrm{Li}$ et al., 2020), and also with increased raffinose content and enhanced chilling tolerance after overexpression of the ZmDREB1A transcription factor (Han et al., 2020). Nonetheless, few studies explored the role of GolS and RafS during cold acclimation in woody tissues.

Although ABA is recognized as a central player in abiotic stress responses (Vishwakarma et al., 2017), like drought and cold, its relation with RFO metabolism is still limited. Interestingly, it was shown that a GolS from Boea hygrometrica (BhGols1) is induced by dehydration and ABA (Wang et al., 2009) and that alfalfa somatic embryos treated with ABA show an increased expression of GolS and accumulation of galactinol, raffinose, and stachyose (Blöchl et al., 2005).

Reports have shown that grapevine synthesizes proline and phenolic compounds and accumulates starch and soluble sugars to overcome cold stress (Ait Barka et al., 2006; Fernandez et al., 2012), but there is still a gap of knowledge concerning the role of RFOs in plant adaptation to cold. In grapevine, VviGolS1 was associated with the response to heat stress by synthesizing galactinol, although the accumulation of raffinose or stachyose was not detected (Pillet et al., 2012). Also, different GolSs are expressed in $V$. amurensis and $V$. vinifera plantlets in response to cold stress (Chai et al., 2019). In this work, 1-year-lignified canes from an important Portuguese regional variety-Vinhão-were harvested at the beginning of autumn and incubated at $4^{\circ} \mathrm{C}$ to simulate cold acclimation. Starch, soluble sugars (sucrose, glucose, fructose, raffinose, and stachyose), and ABA were then quantified after 7 and 14 days of acclimation. Expression analysis of VviGols and VviRafS families was carried out, which allowed the identification of VviRafS5 as a key player in grapevine cold response in woody tissues. The overexpression of VviRafS5 in yeast enabled the in vitro biochemical characterization of the enzyme in protein extracts. Notably, VviRafS5 is upregulated by cold and ABA but not by heat and salt stresses as observed in grapevine cell suspensions.

\section{MATERIALS AND METHODS}

\section{Plant Material}

Field-grown grapevine (V. vinifera L.) canes were collected after fruit harvest from a commercial vineyard of the Controlled Appellation (DOC) region of Vinhos Verdes in the northwest region of Portugal $\left(41^{\circ} 48^{\prime} 45.3^{\prime \prime} \mathrm{N} 8^{\circ} 24^{\prime} 36.4^{\prime \prime} \mathrm{W}\right)$ in 2019. Lignified shoots of similar diameter $(\sim 2 \mathrm{~cm})$ were cut into single bud segments of approximately $15 \mathrm{~cm}$, its basal ends were inserted into wet floral foam, and the top ends were sealed with paraffin film to prevent dehydration, as previously reported (Noronha et al., 2021). Samples were then incubated at $4^{\circ} \mathrm{C}$ for 7 (T1) and 14 days (T2). Shoots not subjected to cold were used immediately after their collection (T0; Figure 1). Control canes were collected in the same conditions, during 2021, and incubated for the same periods at room temperature $\left(20^{\circ} \mathrm{C}\right)$. At each incubation period, three biological replicates (four similar sized canes per replicate) were sampled. The periderm of each sample was removed with a scalpel, frozen with liquid $\mathrm{N}_{2}$ to be ground in a IKA A11 basic analytical mill and stored at $-80^{\circ} \mathrm{C}$. Part of these samples was freeze-dried in a Christ-Alpha 2-4 LD lyophilizer for quantification of raffinose, stachyose, and starch.

Gamay Fréaux cultured cells were grown in liquid Gamborg B5 supplemented with $2 \%(\mathrm{w} / \mathrm{v})$ sucrose and $.025 \%(\mathrm{w} / \mathrm{v})$ casein hydrolysate and maintained in $250 \mathrm{ml}$ flasks on a rotatory shaker at $100 \mathrm{rpm}$ and $24^{\circ} \mathrm{C}$. Cells were subcultured weekly by transferring 


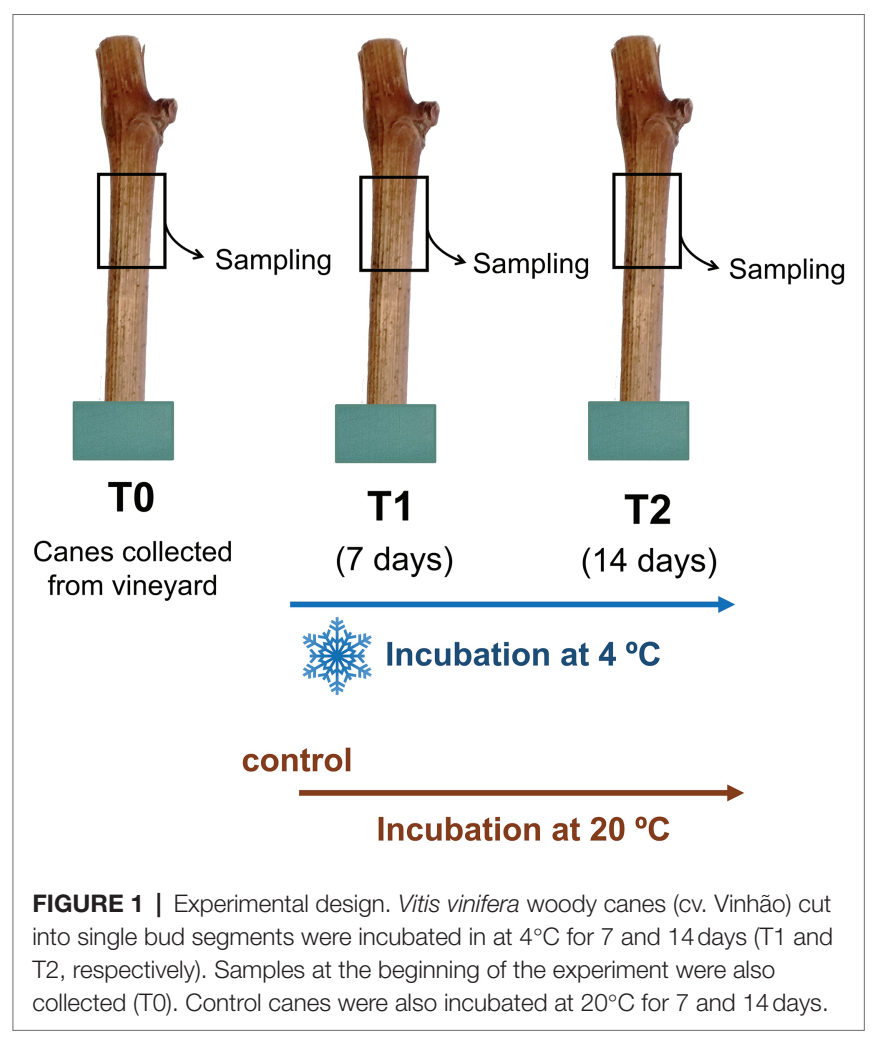

$10 \mathrm{ml}$ aliquots into $40 \mathrm{ml}$ of fresh medium. To study the effect of different temperatures on VviRafs 5 expression, $20 \mathrm{ml}$ aliquots of 6-days-old cells were incubated for $24 \mathrm{~h}$ at 24 (control), 4, and $37^{\circ} \mathrm{C}$. The effect of $100 \mathrm{~mm} \mathrm{NaCl}$ and $100 \mu \mathrm{m} \mathrm{ABA}$ was tested in cells cultivated for $24 \mathrm{~h}$ at $24^{\circ} \mathrm{C}$. Cells were collected by vacuum filtration, ground in liquid $\mathrm{N}_{2}$, and stored at $-80^{\circ} \mathrm{C}$.

\section{Sugar Quantification by High Performance Liquid Chromatography}

The extraction of sugars was performed as reported by Conde et al. (2015) adapted from Eyéghé-Bickong et al. (2012). In short, for sucrose, glucose, and fructose quantification, $150 \mathrm{mg}$ of fresh weight (FW) cane tissue was mixed with $1 \mathrm{ml}$ of ultrapure $\mathrm{H}_{2} \mathrm{O}$, vortexed, and mixed with $1 \mathrm{ml}$ of chloroform. The same procedure was done with lyophilised material for raffinose and stachyose quantification. The biphasic solvent was vortexed for $5 \mathrm{~min}$ and incubated at $50^{\circ} \mathrm{C}$ for $30 \mathrm{~min}$ with continuous shaking ( $150 \mathrm{rpm})$. Samples were then centrifuged at $15000 \times \mathrm{g}$ for $10 \mathrm{~min}$ and the supernatant was collected and filtered with a $.45 \mu \mathrm{m}$ nitrocellulose filter. Sugars were quantified by HPLC-RI with a Rezex RCM-Monosaccharide $\mathrm{Ca}^{2+}(8 \%)$ column (Phenomenex) at a flow rate of $.6 \mathrm{ml} \mathrm{min}^{-1}$ at $40^{\circ} \mathrm{C}$ using water as the mobile phase. Twenty $\mu \mathrm{l}$ of each sample were injected and sugar concentration was measured after the comparison of the peak area and retention time with calibration curves.

\section{Starch Quantification}

Starch was quantified in canes according to Silva et al. (2017). To remove soluble sugars, lyophilized cane tissues (50 mg DW) were extracted three times with $5 \mathrm{ml} 80 \%$ ethanol, and starch grains were gelatinized by autoclaving. Starch was enzymatically degraded by $\alpha$-amylase (AMY; $1 \mathrm{U}$, Sigma-Aldrich) and $\beta$-glucosidase (10 U, Sigma-Aldrich) in a medium containing $200 \mathrm{~mm}$ sodium acetate $(\mathrm{pH} 5.5)$ and released sugars were measured with the DNS method.

\section{In silico Studies}

To identify grapevine RFO gene family members, Arabidopsis thaliana sequences of GolS and RafS were blasted against the genome of $V$. vinifera L. (12X) using the online platform Phytozome. ${ }^{1}$ Annotated genes were named following phylogenetic analysis using amino acid sequences from $V$. vinifera and Arabidopsis thaliana obtained from the National Center of Biotechnology (NCBI) and Uniprot (Supplementary Figure 2). Sequence alignment was performed with PRANKSTER (Whelan and Goldman, 2001) and Genedoc (Nicholas et al., 1997). The phylogenetic tree was constructed using these alignments with PROTDIST, NEIGHBOR, and RETREE from the PHYLIP software package (Felsenstein, 1989) and Mega 4 (Tamura et al., 2007).

\section{RNA Isolation and cDNA Synthesis}

Total RNA from cane tissues and cultured cells was isolated as previously described (Reid et al., 2006) with some adaptations. For each condition, $500 \mathrm{mg}$ of frozen tissue was mixed with $1 \mathrm{ml}$ of extraction buffer containing $300 \mathrm{~mm}$ Tris $\mathrm{HCl}(\mathrm{pH}$ 8.0), $25 \mathrm{~mm}$ EDTA, 2.0 M NaCl, 2\% CTAB, 2\% PVP (K-30), and $30 \mathrm{~mm}$ DTT. Samples were then incubated at $60^{\circ} \mathrm{C}$ for $15 \mathrm{~min}$ and shaken every $5 \mathrm{~min}$. Then, mixtures were extracted twice with $850 \mu$ l of chloroform: isoamyl alcohol (24:1) followed by centrifugation at $15000 \times g$ for $15 \mathrm{~min}$ at $4^{\circ} \mathrm{C}$. Subsequently, $.1 \mathrm{vol}$ of $3 \mathrm{M} \mathrm{NaOAc}(\mathrm{pH} 5.2)$ and $.6 \mathrm{vol}$ of isopropanol were added to the aqueous phase, followed by incubation at $-80^{\circ} \mathrm{C}$ for $1 \mathrm{~h}$. The mixture was centrifuged at $15000 \times g$ at $4^{\circ} \mathrm{C}$ during $30 \mathrm{~min}$ and later resuspended in $100 \mu \mathrm{l}$ of ultrapure $\mathrm{H}_{2} \mathrm{O}$. To purify the samples, the GRS Total RNA Kit-Plant (GriSP, Lda.) was used following the manufacturer's instructions. RNA concentration and purity were quantified spectrophotometrically in the NanoDrop ND-1000 (Thermo Fisher Scientific Inc.) and integrity checked in a $1 \%(\mathrm{w} / \mathrm{v})$ agarose gel. First strand cDNA synthesis was performed using Xpert cDNA Synthesis Mastermix protocol (GriSP, Lda.), according to the manufacturer's instructions.

\section{Real-Time PCR Studies}

Quantitative real-time PCRs were performed with Xpert Fast SYBR Blue (GriSP, Lda.) along with the conditions previously optimized in a CBX96 Real-Time Detection System (Bio-Rad). The amplification protocol included an initial denaturation step at $95^{\circ} \mathrm{C}$ for $3 \mathrm{~min}$, followed by additional 40 cycles of denaturation for $3 \mathrm{~s}$ at $95^{\circ} \mathrm{C}$, annealing for $20 \mathrm{~s}$ at $55^{\circ} \mathrm{C}$, and $20 \mathrm{~s}$ at $72^{\circ} \mathrm{C}$. Experiments were done in biological replicates and then interpreted with the software Bio-Rad CFX Manager (Bio-Rad), while VviGAPDH (glyceraldehyde-3-phosphate dehydrogenase)

\footnotetext{
${ }^{1}$ http://phytozome.jgi.doe.gov
} 
and VviACT1 were used as internal control. The primers used in this study are listed in Supplementary Table 1.

\section{Cloning of VviRafs5 and Its Overexpression in Yeast Cells}

Due to experimental difficulties in using bacterial hosts, gap repair was used to clone VviRafs5 into the pYES-DEST52 vector (V5-epitope; Invitrogen) using Saccharomyces cerevisiae INVSc1 (Bessa et al., 2012). VviRafS5 CDS, without the stop codon (allowing the production of a VviRafS5-V5-epitope fusion protein), was amplified using primers listed on Supplementary Table 1 (VviRafS5-Gap-FW and VviRafS5Gap-RV). Fragment amplification was done using NZYTaq II DNA polymerase (NZYTech, Lda), according to the manufacturer's instructions. pYES-DEST52 (Invitrogen) vector was digested with EcoRI (Thermo Scientific) and SmaI (Thermo Scientific) and purified using GRISP PCR \& Gel Band Purification (GriSP, Lda.). The transformation of INVSc1 yeast was carried out using the LiAc/SS-DNA/PEG method and linearized pYESDEST52 and VviRafS5 PCR product (Gietz and Woods, 2002). As control, yeast cells were also transformed with the empty vector. Transformants were selected on solid synthetic medium: $.7 \%$ YNB (Alfa Aesar), 1.3\% dropout (US Biological; without uracil), .5\% ammonium sulfate, $2 \%$ glucose, and $2 \%$ agar. Positive clones, confirmed by PCR, were cultivated overnight at $30^{\circ} \mathrm{C}$ in liquid synthetic medium with $2 \%(\mathrm{w} / \mathrm{v})$ glucose and protein synthesis was induced by diluting cells to $\mathrm{DO}_{640 \mathrm{~nm}}$ .4 in synthetic medium supplemented with $2 \%$ galactose and allowed to grow overnight at $30^{\circ} \mathrm{C}$. Cells were then collected, washed twice with deionized water, and resuspended in extraction buffer (pH 7.5, $50 \mathrm{~mm}$ HEPES, $25 \mathrm{~mm} \mathrm{NaCl}, 1 \mathrm{~mm}$ PMSF, $1 \mathrm{~mm}$ DTT, and $1 \mathrm{~mm}$ EDTA). Acid-washed glass beads were added and cell lysis was accomplished in the cell disruptor (Scientific) with 3 cycles of $30 \mathrm{~s}$ homogenization followed by $1 \mathrm{~min}$ on ice. The mixture was centrifuged at $16000 \times g$ for $20 \mathrm{~min}$ at $4^{\circ} \mathrm{C}$, the supernatant was collected, and sugars present in the crude protein extracts were removed using a Amicon Ultra-4 10,000 NMWL (Merck), following the manufacturer's instructions. Protein extracts were used to study VviRafS5 activity.

\section{Functional Characterization of VviRafs5}

Protein concentration was assessed with the Bradford assay. To functionally characterize VviRafS5 protein, galactinol and sucrose were used as substrates in saturating concentrations according to $\mathrm{Li}$ et al. (2020). The reaction was conducted in a $200 \mu \mathrm{l}$ reaction system containing reaction buffer $(50 \mathrm{~mm}$ HEPES; pH 7.5), $30 \mathrm{~mm}$ sucrose, $25 \mathrm{~mm}$ galactinol, and $50 \mu \mathrm{l}$ of crude yeast extract. Reactions proceeded for $2 \mathrm{~h}$ at $37^{\circ} \mathrm{C}$. Produced raffinose was measured by HPLC as described above.

\section{Western Blot Analysis}

Protein samples obtained as described above were separated on 10\% acrylamide gels as described by Laemmli (1970). Proteins were transferred to a nitrocellulose membrane during $1.5 \mathrm{~h}$ at $100 \mathrm{~V}$ and were blocked during $1 \mathrm{~h}$ in TRIS-buffered saline containing .1\% (v/v) Tween-20 (TBS-T) with 5\% (w/v) skimmed milk powder. The membranes were probed against V5-tag (Anti-V5 antibody, 1:3000 dilution, Sigma) during $1 \mathrm{~h}$ at room temperature in blocking solution, followed by an incubation with an antirabbit peroxidase-conjugated antibody (Sigma) at 1:10000 dilution in TBS-T, for $45 \mathrm{~min}$. The immunodetection was accomplished with the chemiluminescent ECL detection substrate (Bio-Rad) and observed in the ChemiDoc system (Bio-Rad).

\section{ABA and ABA-Related Metabolites Quantification}

$\mathrm{ABA}$ and $\mathrm{ABA}$ catabolites detection and quantification were performed as reported in Diretto et al. (2020) and Barja et al. (2021). Briefly, $50 \mathrm{mg}$ freeze-dried grounded cane samples were extracted using unbuffered Tris-ethyl acetate as reported before (Welsch et al., 2008). LC-HRMS was carried out using an Ultimate UHPLC system with a photodiode array detector (Dionex), and a Q-exactive quadrupole Orbitrap mass spectrometry system (Thermo Fisher Scientific; LC-HRMS) equipped with an electrospray ionization (HESI) source, operating in negative ion mode, as previously described (Di Meo et al., 2019) with the following modifications: with nitrogen as sheath and auxiliary gas set at 35 and 25 units, respectively. The vaporizer and capillary temperatures were set at 280 and $320^{\circ} \mathrm{C}$, respectively. The discharge current was set to $4.0 \mu \mathrm{A}$ and S-lens $\mathrm{RF}$ level set at 50. Internal standard-based quantification was carried out using the MS data, while retention times and MS2 fragmentation patterns were used for $\mathrm{ABA}$ identification by using authentic reference standards (trans-ABA from OlChemIm and ()-ABA from Sigma, St. Louis, MO, United States).

\section{Statistical Analysis}

The results were statistically analyzed by ANOVA tests (one-way and two-way ANOVA) using Prism vs. 7 (GraphPad Software, Inc.). Statistical differences between mean values are marked with letters for the different conditions or were marked with asterisks $(* p \leq .05 ; * * p<.01 ; * * * p<.001$; and $* * * * p<.0001)$.

\section{RESULTS}

\section{Starch Decreases and Soluble Sugars Increase During Cold Acclimation of Grapevine Canes}

Results showed a steadily reduction in the amount of stored starch in woody canes after cold treatment, from $62.74 \pm 5.90$ at T0 to $48.74 \pm 3.87 \mathrm{mgg} \mathrm{DW}^{-1}$ at T2 (Figure 2A). In parallel to starch degradation, an increase in sucrose levels was observed, from $4.52 \pm .40$ to $7.44 \pm .80 \mathrm{mgg} \mathrm{FW}^{-1}$ at T2 (Figure 2B). Glucose and fructose also increased from $8.31 \pm .51$ and $5.73 \pm .26$, respectively, at T0 to $13.65 \pm .83$ and $9.99 \pm .62 \mathrm{mgg} \mathrm{FW}^{-1}$ at T2 (Figure 2A). Regarding RFOs, raffinose at T2 almost doubled its amount from T0, increasing from $2.70 \pm .44$ to $5.09 \pm .80 \mathrm{mgg}$ $\mathrm{DW}^{-1}$, while a 5 -fold increase in stachyose was observed, from $.65 \pm .02$ at $\mathrm{T} 0$ to $3.40 \pm .53 \mathrm{mgg} \mathrm{DW}^{-1} \mathrm{~T} 2$ (Figure 2C). Canes incubated at room temperature showed no changes in raffinose and stachyose content (Figure 2, inset). 
A

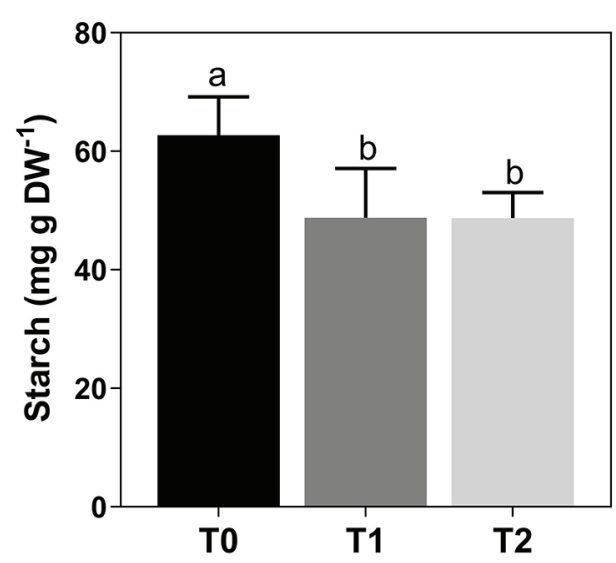

C

B
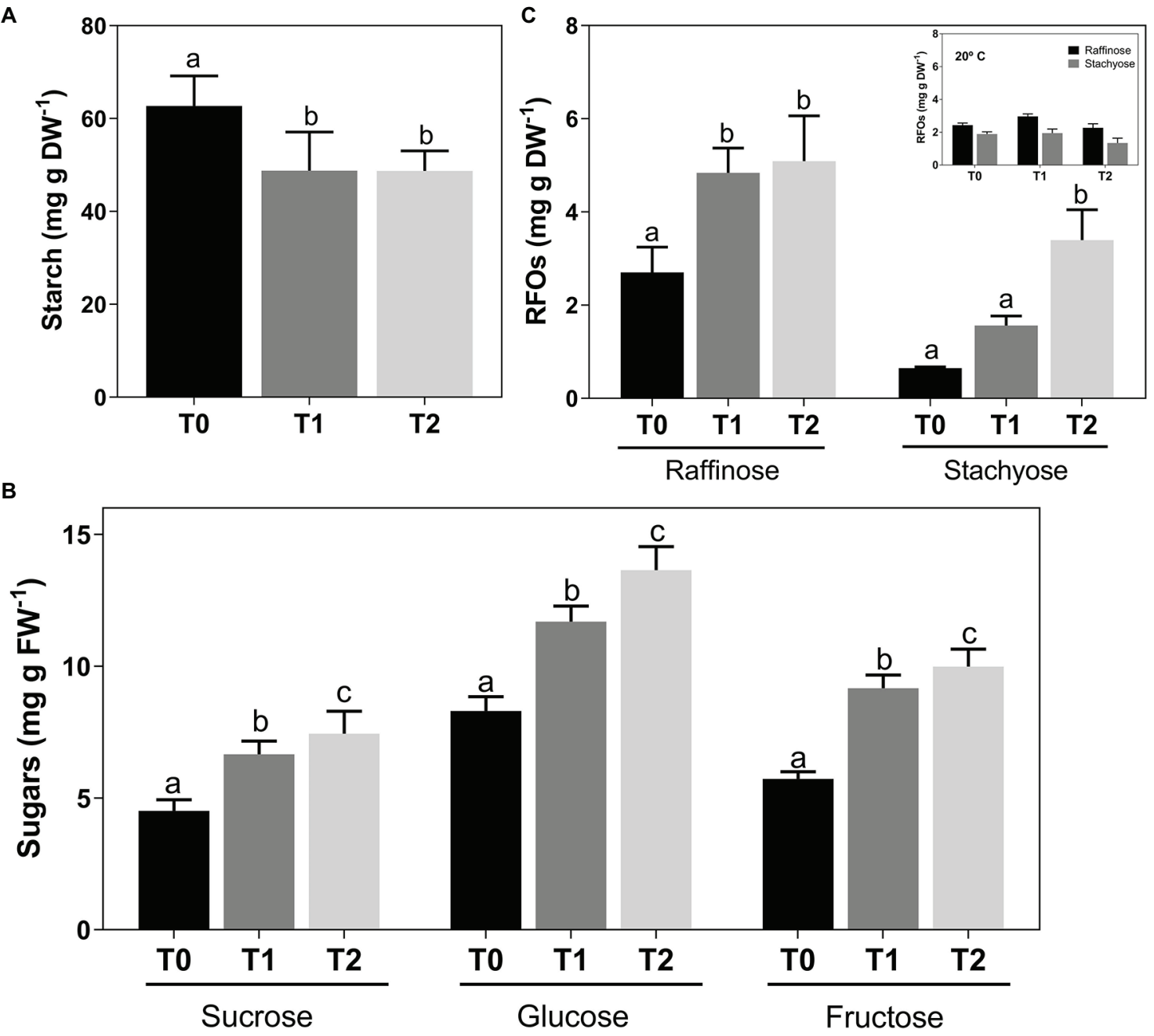

FIGURE 2 | Concentration of sucrose, glucose, and fructose (A), starch (B) and raffinose, and stachyose (C) in Vitis vinifera cv. Vinhão canes incubated at $4{ }^{\circ} \mathrm{C}$ up to 14 days. Insert, raffinose, and stachyose levels in canes incubated at $20^{\circ} \mathrm{C}$ up to 14 days. Results indicate the mean \pm SD of three biological replicates per condition. Different letters stand for significant differences $(p \leq .05)$.

\section{ABA Is Involved in the Cold Response of Grapevine Canes}

ABA and ABA-related metabolites were quantified in grapevine woody tissues by LC-HRMS. Results showed that ABA increased from T0 to T2 together with ABA-glucoside and dihydrophaseic acid, while phaseic acid decreased (Figure 3A). Accordingly, the expression of VviNCED2 and VviNCED3, which code for 9-cis-epoxycarotenoid dioxygenases and are considered major control points of ABA synthesis, was upregulated following cold treatment (Figure 3B).

\section{Cold Promotes a Transcriptional Modification of Key Genes Involved in RFOs Metabolism}

Real-Time PCR analysis was performed to determine the expression of genes coding for enzymes responsible for the synthesis of RFOs during cold adaptation of grapevine woody tissues (Figure 4).
Eight raffinose synthase genes, VviRafS1-8, and one stachyose synthase, VviStaS1, were identified (Supplementary Figure 3) and their expression in grapevine woody tissues following incubation at $4^{\circ} \mathrm{C}$ was analyzed (Figure 4B). VviRafS1, -3 , and -4 were not transcriptionally modified in response to cold and VviStaS1 and VviRafS2 and -7 were not detected by qPCR in these tissues. On the contrary, the steady-state transcript levels of VviRafS6 increased by up to 6-fold compared to T0 the expression of VviRafS5 and -8 was strongly upregulated up to 40 -fold. Furthermore, results showed that cold treatment strongly upregulated the expression of VviGolS1 and VviGolS3, which are key enzymes in galactinol synthesis (Figure 4B).

\section{VviRafS5 Codes for an Active Enzyme in Yeast Cells}

VviRafS5 was cloned into S. cerevisiae strain INVSc1 and its ability to synthesize raffinose in vitro was studied by HPLC 


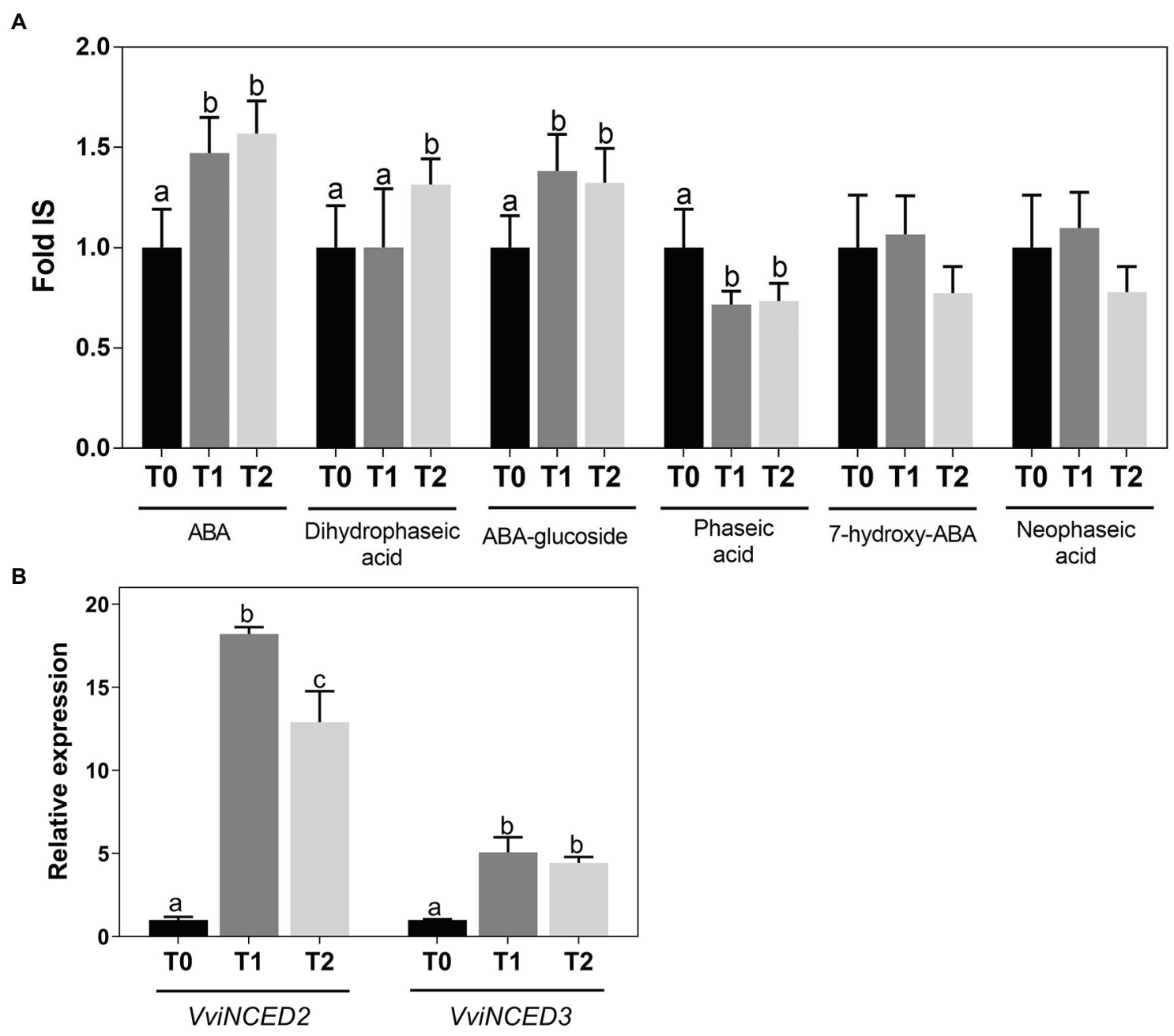

FIGURE 3 | Quantification of ABA and ABA-related metabolites by LC-HRMS (A) and expression of VviNCED genes (B) in Vitis vinifera cV. Vinhão canes incubated at $4^{\circ} \mathrm{C}$ up to 14 days. Results indicate the mean \pm SD of three biological replicates per condition. Different letters stand for significant differences $(p \leq .05)$.

(Figure 5). Results showed that yeast protein extracts containing VviRafS5-V5-tag are able to synthesize raffinose in the presence of saturating galactinol and sucrose (Figures 5A,B). Also, the presence of VviRafS5-V5-tag in yeast protein extracts was confirmed by Western blot using an anti-V5 antibody, with a molecular weight of $\sim 87 \mathrm{kDa}$ (Figure 5C).

\section{VviRafS5 Transcriptional Regulation by Different Stresses}

Because VviRafS5 was the most expressed raffinose synthase in woody tissues during cold treatment, its transcription was studied in different grapevine organs (canes, leaves, flowers, and roots) and berries at two development stages (green and mature). Results showed that VviRafS5 is mainly expressed in mature berries, but also in flowers and roots (Figure 6A). Following previous results showing that RafS is responsive to different abiotic stresses (Egert et al., 2013) and the identification of several cis-regulatory elements involved in abiotic stresses and ABA responses in VviRafS5 promotor (Figure 6B), cultured cells of cv. Gamay Fréaux were subjected to different temperatures and elicited with salt and ABA to check their effect on the expression of VviRafS5. In agreement with previous data, the steady-state transcript levels of VviRafS5 resulted higher after cold (2.4-fold) and ABA treatments (1.7-fold), and lower (.2-fold) after heat treatment. On the contrary, salt stress did not affect significantly the expression of VviRafS5 (Figure 6C).

\section{DISCUSSION}

In this study, the accumulation of sugars in grapevine woody tissues in response to cold was explored using an in vitro approach to mimic winter cold acclimation. The general accumulation of soluble sugars in grapevine cv. Vinhão in response to cold is in agreement with previous studies. A similar result was obtained in field-grown cv. Riesling and Chardonnay vines (Hamman et al., 1996; Todaro and Dami, 2017). This cold-induced sugar increase most likely comes from 


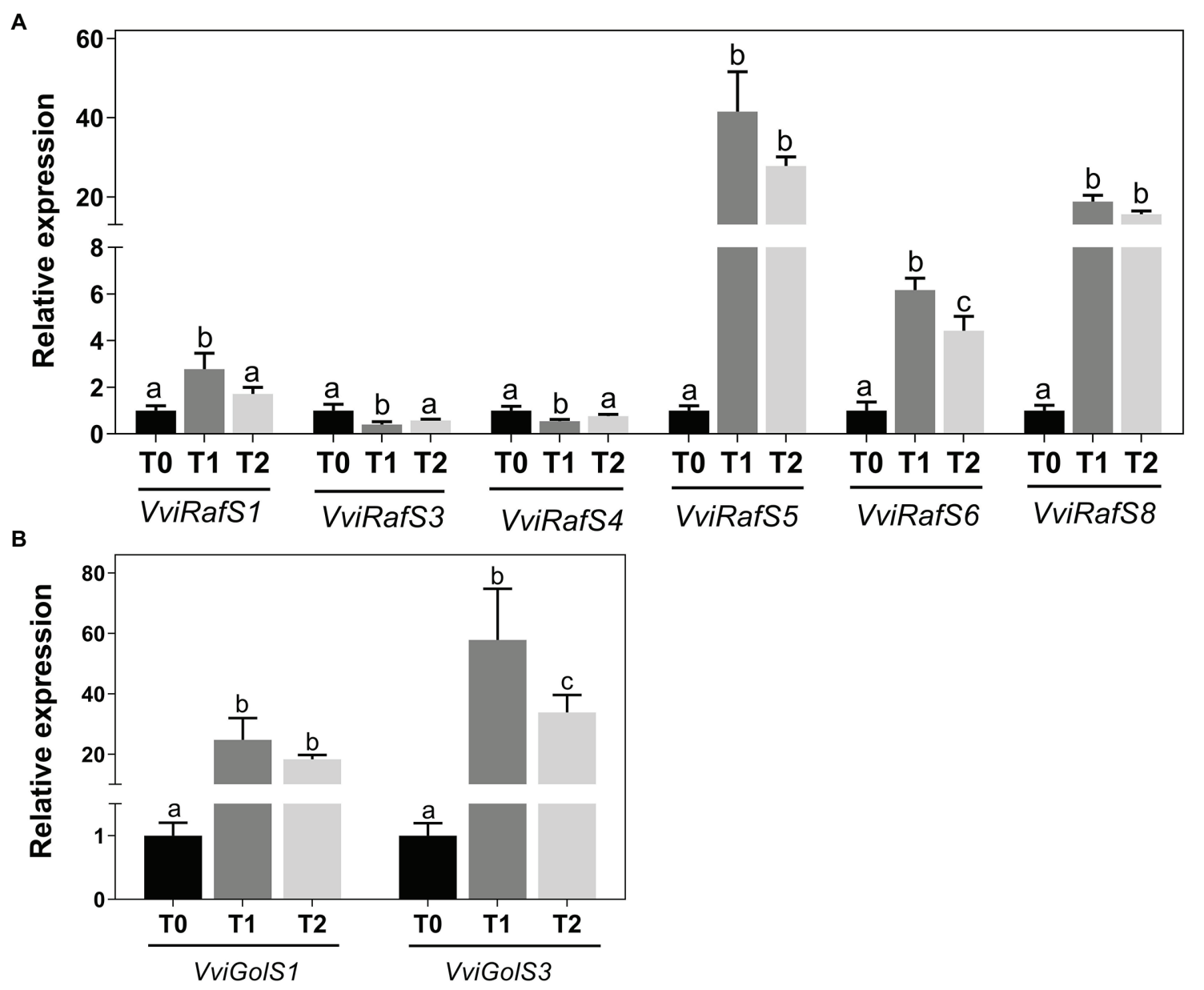

FIGURE 4 | Transcriptional analysis of VviGo/Ss (A) and VviRafSs (B) in Vitis vinifera cv. Vinhão canes incubated at $4^{\circ} \mathrm{C}$ up to 14 days. Results indicate the mean \pm SD of three biological replicates per condition. Different letters stand for significant differences $(p \leq .05)$.

starch degradation because a concomitant decrease in this polymeric carbohydrate was observed. This pattern of starch degradation and synthesis of compatible solutes during winter has been also described in the wood of different plants, including poplar (Sauter, 1988; Sauter and van Cleve, 1990), Cornus sericea (Ashworth et al., 1993), and willow (Ögren, 1999). Nonetheless, starch degradation may, to some extent, fuel other cellular processes considering the artificial system used in this study, but no raffinose synthesis was observed at room temperature supporting a specific role of RFOs in plant response to cold.

In the present study, we observed that within six raffinose synthase and one stachyose synthase genes identified, VviRafS5 and VviRafS8 seem to play pivotal roles during cold treatment of grapevine canes. Furthermore, VviRafS6, which was recently associated with grapevine cold response in plantlets (Chai et al., 2019), was also upregulated in woody tissues. To the best of our knowledge, the present study is innovative regarding the characterization of RafS in woody tissues of grapevine. In particular, we confirmed that VviRafS5, which was transcriptionally upregulated up to 40 -fold in response to cold, is able to synthesize raffinose in vitro after its heterologous expression in yeast. Thus, the accumulation of raffinose in grapevine perennial organs by VviRafS5 may constitute an important metabolic adjustment in response to cold acclimation, alone or in cooperation with other VviRafS. Interestingly, despite the observed stachyose accumulation in canes, the expression of VviStaS1 was not detected in this study, suggesting that in these tissues this RFO is synthesized by a putative RafS, as previously found in Arabidopsis thaliana (Gangl and Tenhaken, 2016), or by other still unidentified enzyme.

The results obtained in Gamay Fréaux cultured cells also corroborated the role of VviRafS5 in cold response. However, in Arabidopsis thaliana seeds, the orthologue AtRafS5 is responsible for raffinose accumulation in response to different stresses, including cold, heat, and drought (Egert et al., 2013; Gangl and Tenhaken, 2016). Therefore, future studies could address the role of RFOs in grapevine response to other abiotic stresses besides cold, including drought and heat, together with the characterization of genes/proteins involved on its biosynthesis. Furthermore, additional studies are still needed to clarify whether VviRafS 8 and VviRafS6 are indeed grapevine raffinose synthase 


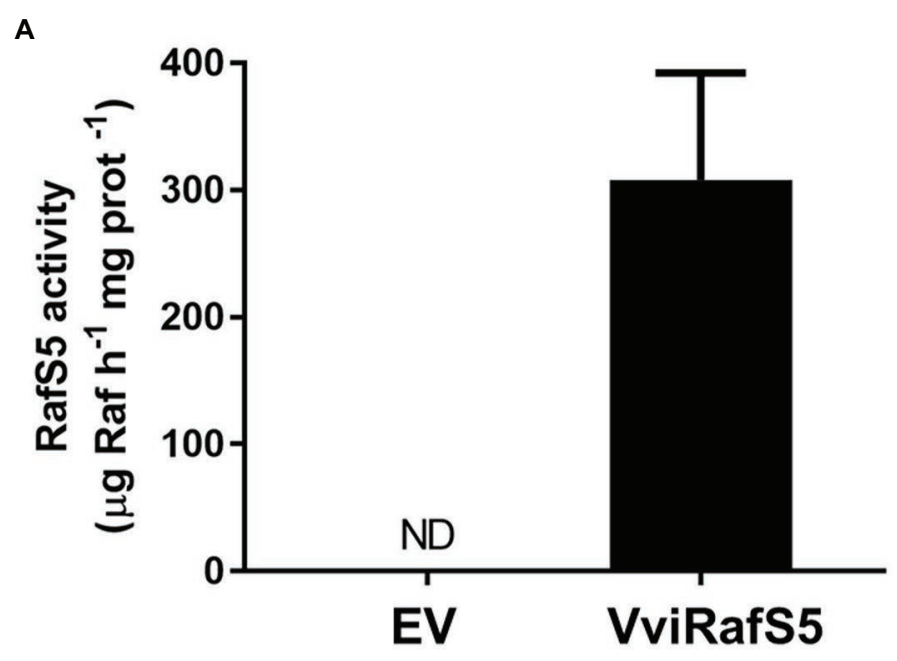

B

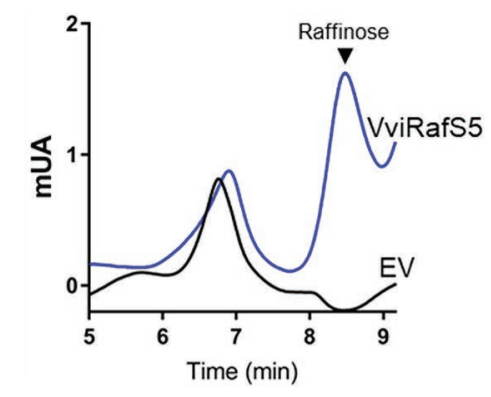

C
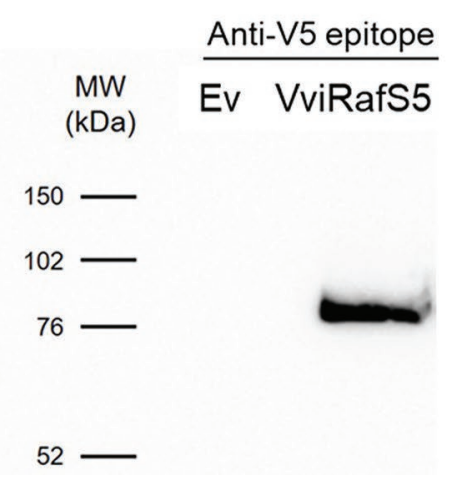

FIGURE 5 | Functional characterization of VViRafS5. Production of raffinose in protein lysates from INVSc1 yeast expressing VviRafS5:V5-tag, or the empty vector (EV), when incubated with sucrose and galactinol (A). Raffinose synthesis was determined by HPLC (B). Protein production was confirmed trough Western blotting using anti-V5 antibody (C).

enzymes because it has been previously shown that several RafS from Arabidopsis thaliana is not involved in raffinose accumulation (Egert et al., 2013) and AtSIP2, previously annotated as a raffinose synthase gene, codes a raffinose-degrading $\alpha$-galactosidase (Peters et al., 2010). Thus, the characterization of the biochemical activities of these enzymes in planta is of the utmost scientific relevance.

The observation in the present work that VviRafS5 is highly expressed in mature grape berries also deserves further attention because these fruits also contain raffinose (Kliewer, 1964). Given the already established role of RFOs accumulation in response to drought (Egert et al., 2015; Li et al., 2020), it is highly plausible that both raffinose and stachyose, whose synthesis could be mediated by VviRafS5 and other RafS, may have such functions in mature berries.

It is well known that, besides having a central role in seed dormancy, abscission, and abiotic stress signaling, ABA is pivotal in the plant response to low temperature (Eremina et al., 2015). In grapevine buds, the role of ABA during bud dormancy acquisition (Düring and Bachmann, 1975; Koussa et al., 1994; Or et al., 2000) and release (Zheng et al., 2015) is consensual. Although the site of ABA formation and its transport are still a matter of debate (McAdam and Brodribb, 2018), it has recently been reported that phloem companion cells, guard cells, and mesophyll cells are able to synthesize this hormone (Bauer et al., 2013; Kuromori et al., 2014; McAdam and Brodribb, 2018). Remarkably, our results strongly suggested that grapevine woody tissues are able to de novo synthesize ABA during cold incubation, which is also an important novelty of the present study. In this regard, not only the levels of $\mathrm{ABA}$ and its catabolites were higher during cold acclimation, but also the expression of $V v i N C E D 2$ and -3 genes was upregulated. VviNCED2 and -3 code for 9-cis-epoxycarotenoid dioxygenases and thus are considered major control points of ABA synthesis. Their role in the accumulation of this hormone in grapevine is well known in grapevine buds (Zheng et al., 2015) and plantlets (He et al., 2018), as well as in other species like Arabidopsis thaliana (Lefebvre et al., 2006), tobacco (Qin and Zeevaart, 2002), and tomato (Thompson et al., 2000). Taken together, our results suggest that ABA upregulates VviGolS and VviRafS in grapevine woody tissues during cold acclimation, promoting an accumulation of RFOs, as previously shown in Boea hygrometrica (Wang et al., 2009) and alfalfa (Blöchl et al., 2005). Nonetheless, the ABA regulatory network in grapevine woody tissues during cold incubation needs to be further explored, particularly the identification of the transcription factors behind VviGolS and VviRafS increased expression. Also, and despite that no changes were found in the expression levels of VviBAMs (Supplementary Figure 3), the role of the CBF regulon in RFO synthesis should be explored, since it has been shown that Gols is a target of these regulatory network (Taji et al., 2002; Tarkowski and Van den Ende, 2015). Furthermore, additional evidence is 


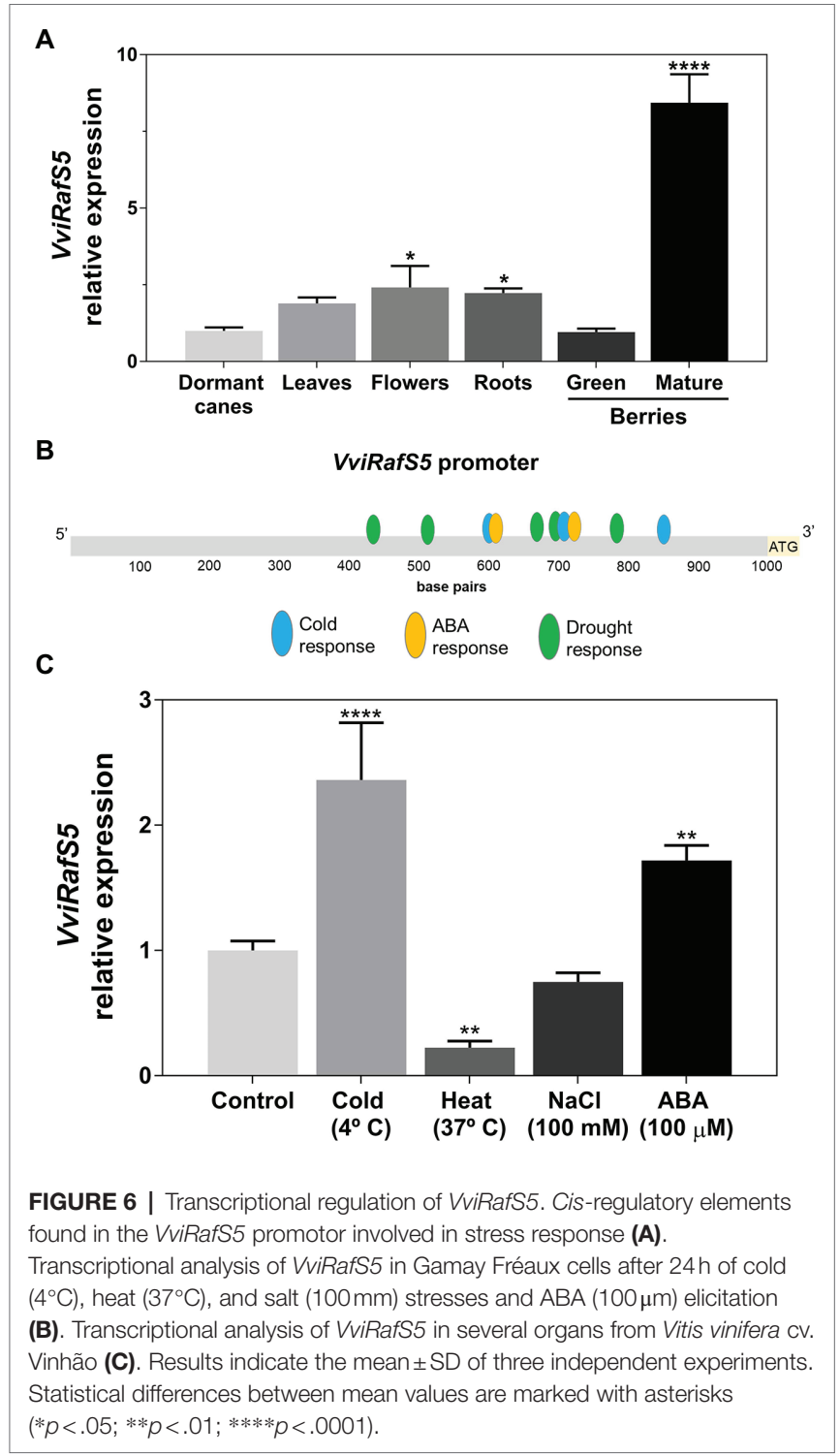

still necessary to clarify the molecular mechanisms involved in grapevine against cold stress mediated by raffinose and other RFOs.

\section{REFERENCES}

Ait Barka, E., Nowak, J., and Clément, C. (2006). Enhancement of chilling resistance of inoculated grapevine plantlets with a plant growth-promoting rhizobacterium, Burkholderia phytofirmans strain PsJN. Appl. Environ. Microbiol. 72, 7246-7252. doi: 10.1128/AEM.01047-06

Antivilo, F. G., Paz, R. C., Tognetti, J., Keller, M., Cavagnaro, M., Barrio, E. E., et al. (2020). Winter injury to grapevine secondary phloem and cambium impairs budbreak, cambium activity, and yield formation. J. Plant Growth Regul. 39, 1095-1106. doi: 10.1007/s00344-019-10051-w

Ashworth, E. N., Stirm, V. E., and Volenec, J. J. (1993). Seasonal variations in soluble sugars and starch within woody stems of corms sericea L. Tree Physiol. 13, 379-388. doi: 10.1093/treephys/13.4.379

Barja, M. V., Ezquerro, M., Beretta, S., Diretto, G., Florez-Sarasa, I., Feixes, E., et al. (2021). Several geranylgeranyl diphosphate synthase isoforms supply

\section{DATA AVAILABILITY STATEMENT}

The original contributions presented in the study are included in the article/Supplementary Material, and further inquiries can be directed to the corresponding author.

\section{AUTHOR CONTRIBUTIONS}

HN and HG conceptualized the work and wrote the manuscript. HN, AS, and TS performed laboratory sample processing, biochemical analysis, targeted transcriptomics, and heterologous expression. SF and GD performed metabolomic analysis and data treatment. $\mathrm{HN}, \mathrm{HG}$, and GD analyzed the results. AS, TS, GD, HN, SF, and HG reviewed the manuscript. All authors contributed to the article and approved the submitted version.

\section{FUNDING}

The work was supported by National Funds by FCTPortuguese Foundation for Science and Technology, under the strategic program UIDB/04050/2020. The work was also supported by FCT and European Funds (FEDER/POCI/ COMPETE2020) through the research projects MitiVineDrought (PTDC/BIAFBT/30341/2017 and POCI01-0145-FEDER-030341), BerryPlastid (PTDC/ BIA-FBT/28165/2017 and POCI-01-0145-FEDER-028165), and AgrifoodXXI (NORTE-01-0145-FEDER-000041). AS and HN were supported by FCT grants SFRH/BD/135782/2018 and SFRH/BPD/115518/2016, respectively. This work also benefited from the networking activities within COST ACTION CA17111 INTEGRAPE and Collaborative Laboratory "CoLab ADVID Vines \& Wines."

\section{SUPPLEMENTARY MATERIAL}

The Supplementary Material for this article can be found online at: https://www.frontiersin.org/articles/10.3389/fpls.2021.754537/ full\#supplementary-material

metabolic substrates for carotenoid biosynthesis in tomato. New Phytol. 231, 255-272. doi: 10.1111/nph.17283

Bauer, H., Ache, P., Lautner, S., Fromm, J., Hartung, W., Al-Rasheid, K. A. S., et al. (2013). The Stomatal response to reduced relative humidity requires guard cell-autonomous ABA synthesis. Curr. Biol. 23, 53-57. doi: 10.1016/j. cub.2012.11.022

Bessa, D., Pereira, F., Moreira, R., Johansson, B., and Queirós, O. (2012). Improved gap repair cloning in yeast: treatment of the gapped vector with Taq DNA polymerase avoids vector self-ligation. Yeast 29, 419-423. doi: 10.1002/yea.2919

Blöchl, A., Grenier-de March, G., Sourdioux, M., Peterbauer, T., and Richter, A. (2005). Induction of raffinose oligosaccharide biosynthesis by abscisic acid in somatic embryos of alfalfa (Medicago sativa L.). Plant Sci. 168, 1075-1082. doi: 10.1016/j.plantsci.2004.12.004

Bock, A., Sparks, T. H., Estrella, N., and Menzel, A. (2013). Climate-induced changes in grapevine yield and must sugar content in Franconia (Germany) 
between 1805 and 2010. PLoS One 8:e69015. doi: 10.1371/journal. pone. 0069015

Chai, F., Liu, W., Xiang, Y., Meng, X., Sun, X., Cheng, C., et al. (2019). Comparative metabolic profiling of Vitis amurensis and Vitis vinifera during cold acclimation. Hortic. Res. 6:8. doi: 10.1038/s41438-018-0083-5

Conde, A., Regalado, A., Rodrigues, D., Costa, J. M., Blumwald, E., Chaves, M. M., et al. (2015). Polyols in grape berry: transport and metabolic adjustments as a physiological strategy for water stress tolerance in grapevine. J. Exp. Bot. 66, 889-906. doi: 10.1093/jxb/eru446

Di Meo, F., Aversano, R., Diretto, G., Demurtas, O. C., Villano, C., Cozzolino, S., et al. (2019). Anti-cancer activity of grape seed semi-polar extracts in human mesothelioma cell lines. J. Funct. Foods 61:103515. doi: 10.1016/j. jff.2019.103515

Dietze, M. C., Sala, A., Carbone, M. S., Czimczik, C. I., Mantooth, J. A., Richardson, A. D., et al. (2014). Nonstructural carbon in woody plants. Annu. Rev. Plant Biol. 65, 667-687. doi: 10.1146/annurev-arplant-050213-040054

Diretto, G., Frusciante, S., Fabbri, C., Schauer, N., Busta, L., Wang, Z., et al. (2020). Manipulation of $\beta$-carotene levels in tomato fruits results in increased ABA content and extended shelf life. Plant Biotechnol. J. 18, 1185-1199. doi: $10.1111 /$ pbi. 13283

Düring, H., and Bachmann, O. (1975). Abscisic acid analysis in Vitis vinifera in the period of endogenous bud dormancy by high pressure liquid chromatography. Physiol. Plant. 34, 201-203. doi: 10.1111/j.1399-3054.1975. tb03821.x

Egert, A., Eicher, B., Keller, E., and Peters, S. (2015). Evidence for water deficitinduced mass increases of raffinose family oligosaccharides (RFOs) in the leaves of three Craterostigma resurrection plant species. Front. Physiol. 6:206. doi: $10.3389 /$ fphys.2015.00206

Egert, A., Keller, F., and Peters, S. (2013). Abiotic stress-induced accumulation of raffinose in Arabidopsis leaves is mediated by a single raffinose synthase (RS5, At5g40390). BMC Plant Biol. 13:218. doi: 10.1186/1471-2229-13-218

Eremina, M., Rozhon, W., and Poppenberger, B. (2015). Hormonal control of cold stress responses in plants. Cell. Mol. Life Sci. 73, 797-810. doi: 10.1007/ s00018-015-2089-6

Eyéghé-Bickong, H. A., Alexandersson, E. O., Gouws, L. M., Young, P. R., and Vivier, M. A. (2012). Optimisation of an HPLC method for the simultaneous quantification of the major sugars and organic acids in grapevine berries. J. Chromatogr. 885, 43-49. doi: 10.1016/j.jchromb.2011.12.011

Felsenstein, J. (1989). PHYLIP-phylogeny inference package (version 3.2). Cladistics 5, 164-166.

Fennell, A. (2004). Freezing tolerance and injury in grapevines. J. Crop Improv. 10, 201-235. doi: 10.1300/J411v10n01_09

Fernandez, O., Theocharis, A., Bordiec, S., Feil, R., Jacquens, L., Clément, C., et al. (2012). Burkholderia phytofirmans PsJN acclimates grapevine to cold by modulating carbohydrate metabolism. Mol. Plant-Microbe Interact. 25, 496-504. doi: 10.1094/MPMI-09-11-0245

Gangl, R., and Tenhaken, R. (2016). Raffinose family oligosaccharides act as galactose stores in seeds and are required for rapid germination of Arabidopsis in the dark. Front. Plant Sci. 7:1115. doi: 10.3389/fpls.2016.01115

Gietz, R. D., and Woods, R. A. (2002). Transformation of yeast by lithium acetate/single-stranded carrier DNA/polyethylene glycol method. Methods in Enzymology 350, 87-96. doi: 10.1016/S0076-6879(02)50957-5

Grant, T. N., Dami, I. E., Ji, T., Scurlock, D., and Streeter, J. (2009). Variation in leaf and bud soluble sugar concentration among Vitis genotypes grown under two temperature regimes. Can. J. Plant Sci. 89, 961-968. doi: 10.4141/CJPS08188

Hamman, R. A., Dami, I.-E., Walsh, T. M., and Stushnoff, C. (1996). Seasonal carbohydrate changes and cold hardiness of chardonnay and Riesling grapevines. Am. J. Enol. Vitic. 47, 31-36.

Han, Q., Qi, J., Hao, G., Zhang, C., Wang, C., Dirk, L. M. A., et al. (2020). ZmDREB1A regulates raffinose synthase controlling raffinose accumulation and plant chilling stress tolerance in maize. Plant Cell Physiol. 61, 331-341. doi: $10.1093 / \mathrm{pcp} / \mathrm{pcz} 200$

He, R., Zhuang, Y., Cai, Y., Agüero, C. B., Liu, S., Wu, J., et al. (2018). Overexpression of 9-cis-epoxycarotenoid dioxygenase cisgene in grapevine increases drought tolerance and results in pleiotropic pffects. Front. Plant Sci. 9:970. doi: 10.3389/fpls.2018.00970

Hendrickson, L., Ball, M., Wood, J., Chow, W. S., and Furbank, R. T. (2004). Low temperature effects on photosynthesis and growth of grapevine. Plant Cell Environ. 27, 795-809. doi: 10.1111/J.1365-3040.2004.01184.X
Kaplan, F., Kopka, J., Haskell, D. W., Zhao, W., Schiller, K. C., Gatzke, N., et al. (2004). Exploring the temperature-stress metabolome of Arabidopsis. Plant Physiol. 136, 4159-4168. doi: 10.1104/pp.104.052142

Kliewer, W. M. (1964). Influence of environment on metabolism of organic acids and carbohydrates in Vitis vinifera. I. Temperature. Plant Physiol. 39, 869-880. doi: 10.1104/pp.39.6.869

Koussa, T., Broquedis, M., and Bouard, J. (1994). Changes of abscisic acid level during the development of grapevine latent buds, particularly in the phase of dormancy break. Vitis 33, 63-67.

Kuromori, T., Sugimoto, E., and Shinozaki, K. (2014). Intertissue signal transfer of Abscisic acid from vascular aells to guard cells. Plant Physiol. 164, 1587-1592. doi: 10.1104/pp.114.235556

Laemmli, U. K. (1970). Cleavage of structural proteins during the assembly of the head of bacteriophage T4. Nature 227, 680-685. doi: 10.1038/227680a0

Lefebvre, V., North, H., Frey, A., Sotta, B., Seo, M., Okamoto, M., et al. (2006). Functional analysis of Arabidopsis NCED6 and NCED9 genes indicates that ABA synthesized in the endosperm is involved in the induction of seed dormancy. Plant J. 45, 309-319. doi: 10.1111/j.1365-313X.2005.02622.x

Li, T., Zhang, Y., Liu, Y., Li, X., Hao, G., Han, Q., et al. (2020). Raffinose synthase enhances drought tolerance through raffinose synthesis or galactinol hydrolysis in maize and Arabidopsis plants. J. Biol. Chem. 295, 8064-8077. doi: $10.1074 /$ jbc.RA120.013948

Liu, Y., Zhang, L., Meng, S., Liu, Y., Zhao, X., Pang, C., et al. (2020). Expression of galactinol synthase from Ammopiptanthus nanus in tomato improves tolerance to cold stress. J. Exp. Bot. 71, 435-449. doi: 10.1093/ jxb/erz450

Mahajan, S., and Tuteja, N. (2005). Cold, salinity and drought stresses: an overview. Arch. Biochem. Biophys. 444, 139-158. doi: 10.1016/j.abb.2005.10.018

McAdam, S. A. M., and Brodribb, T. J. (2018). Mesophyll cells are the main site of abscisic acid biosynthesis in water-stressed leaves. Plant Physiol. 177, 911-917. doi: 10.1104/pp.17.01829

Nicholas, K. B., Nicholas, H. B. Jr., and Deerfeld, D. W. (1997). GeneDoc: analysis and visualization of genetic variation. Embnew. news 4:14

Noronha, H., Garcia, V., Silva, A., Delrot, S., Gallusci, P., and Gerós, H. (2021). Molecular reprogramming in grapevine woody tissues at bud burst. Plant Sci. 311:110984. doi: 10.1016/j.plantsci.2021.110984

Ögren, E. (1999). Fall frost resistance in willows used for biomass production. II. Predictive relationships with sugar concentration and dry matter content. Tree Physiol. 19, 755-760. doi: 10.1093/treephys/19.11.755

Or, E., Belausov, E., Popilevsky, I., and Bental, Y. (2000). Changes in endogenous ABA level in relation to the dormancy cycle in grapevines grown in a hot climate. J. Hortic. Sci. Biotechnol. 75, 190-194. doi: 10.1080/14620316. 2000.11511221

Peterbauer, T., Mach, L., Mucha, J., and Richter, A. (2002). Functional expression of a cDNA encoding pea (Pisum sativum L.) raffinose synthase, partial purification of the enzyme from maturing seeds, and steady-state kinetic analysis of raffinose synthesis. Planta 215, 839-846. doi: 10.1007/s00425002-0804-7

Peters, S., Egert, A., Stieger, B., and Keller, F. (2010). Functional identification of Arabidopsis ATSIP2 (At3g57520) as an alkaline $\alpha$-galactosidase with a substrate specificity for raffinose and an apparent sink-specific expression pattern. Plant Cell Physiol. 51, 1815-1819. doi: 10.1093/pcp/pcq127

Pillet, J., Egert, A., Pieri, P., Lecourieux, F., Kappel, C., Charon, J., et al. (2012). VvGOLS1 and VvHsfA2 are involved in the heat stress responses in grapevine berries. Plant Cell Physiol. 53, 1776-1792. doi: 10.1093/pcp/pcs121

Qin, X., and Zeevaart, J. A. (2002). Overexpression of a 9-cis-epoxycarotenoid dioxygenase gene in Nicotiana plumbaginifolia increases abscisic acid and phaseic acid levels and enhances drought tolerance. Plant Physiol. 128, 544-551. doi: 10.1104/pp.010663

Reid, K. E., Olsson, N., Schlosser, J., Peng, F., and Lund, S. T. (2006). An optimized grapevine RNA isolation procedure and statistical determination of reference genes for real-time RT-PCR during berry development. BMC Plant Biol. 6:27. doi: 10.1186/1471-2229-6-27

Sauter, J. J. (1988). Temperature-induced changes in starch and sugars in the stem of Populus $\times$ canadensis «robusta». J. Plant Physiol. 132, 608-612. doi: 10.1016/S0176-1617(88)80263-3

Sauter, J. J., and van Cleve, B. (1990). Biochemical, immunochemical, and ultrastructural studies of protein storage in poplar (Populus $\times$ canadensis 'robusta') wood. Planta 183, 92-100. doi: 10.1007/BF00197572 
Sengupta, S., Mukherjee, S., Basak, P., and Majumder, A. L. (2015). Significance of galactinol and raffinose family oligosaccharide synthesis in plants. Front. Plant Sci. 6:656. doi: 10.3389/fpls.2015.00656

Shimozaka, E., and Ozawa, K. (2015). Overexpression of cold-inducible wheat galactinol synthase confers tolerance to chilling stress in transgenic rice. Breed. Sci. 65, 363-371. doi: 10.1270/jsbbs.65.363

Silva, A., Noronha, H., Dai, Z., Delrot, S., and Gerós, H. (2017). Low sourcesink ratio reduces reserve starch in grapevine woody canes and modulates sugar transport and metabolism at transcriptional and enzyme activity levels. Planta 246, 525-535. doi: 10.1007/s00425-017-2708-6

Sun, X., Matus, J. T., Wong, D. C. J., Wang, Z., Chai, F., Zhang, L., et al. (2018). The GARP/MYB-related grape transcription factor AQUILO improves cold tolerance and promotes the accumulation of raffinose family oligosaccharides. J. Exp. Bot. 69, 1749-1764. doi: 10.1093/jxb/ery020

Taji, T., Ohsumi, C., Iuchi, S., Seki, M., Kasuga, M., Kobayashi, M., et al. (2002). Important roles of drought- and cold-inducible genes for galactinol synthase in stress tolerance in Arabidopsis thaliana. Plant J. 29, 417-426. doi: 10.1046/j.0960-7412.2001.01227.x

Tamura, K., Dudley, J., Nei, M., and Kumar, S. (2007). MEGA4: molecular evolutionary genetics analysis (MEGA) software version 4.0. Mol. Biol. Evol. 24, 1596-1599. doi: 10.1093/molbev/msm092

Tarkowski, Ł. P., and Van den Ende, W. (2015). Cold tolerance triggered by soluble sugars: a multifaceted countermeasure. Front. Plant Sci. 6:203. doi: 10.3389/fpls.2015.00203

Theocharis, A., Clément, C., and Ait Barka, E. (2012). Physiological and molecular changes in plants grown at low temperatures. Planta 235, 1091-1105. doi: $10.1007 /$ s00425-012-1641-y

Thomashow, M. F. (1999). Plant cold acclimation: freezing tolerance genes and regulatory mechanisms. Annu. Rev. Plant Physiol. Plant Mol. Biol. 50, 571-599. doi: 10.1146/annurev.arplant.50.1.571

Thompson, A. J., Jackson, A. C., Symonds, R. C., Mulholland, B. J., Dadswell, A. R., Blake, P. S., et al. (2000). Ectopic expression of a tomato 9-cis-epoxycarotenoid dioxygenase gene causes over-production of abscisic acid. Plant J. 23, 363-374. doi: 10.1046/j.1365-313x.2000.00789.x

Todaro, T. M., and Dami, I. E. (2017). Cane morphology and anatomy influence freezing tolerance in Vitis vinifera cabernet franc. Int. J. Fruit Sci. 17, 391-406. doi: 10.1080/15538362.2017.1330667

Vinson, C. C., Mota, A. P. Z., Porto, B. N., Oliveira, T. N., Sampaio, I., Lacerda, A. L., et al. (2020). Characterization of raffinose metabolism genes uncovers a wild Arachis galactinol synthase conferring tolerance to abiotic stresses. Sci. Rep. 10:15258. doi: 10.1038/s41598-020-72191-4

Vishwakarma, K., Upadhyay, N., Kumar, N., Yadav, G., Singh, J., Mishra, R. K., et al. (2017). Abscisic acid signaling and abiotic stress tolerance in plants: a review on current knowledge and future prospects. Front. Plant Sci. 8:161. doi: $10.3389 / \mathrm{fpls} .2017 .00161$

Wang, Z., Zhu, Y., Wang, L., Liu, X., Liu, Y., Phillips, J., et al. (2009). A WRKY transcription factor participates in dehydration tolerance in Boea hygrometrica by binding to the $\mathrm{W}$-box elements of the galactinol synthase (BhGolS1) promoter. Planta 230, 1155-1166. doi: 10.1007/s00425-009-1014-3

Welsch, R., Wüst, F., Bär, C., Al-Babili, S., and Beyer, P. (2008). A third phytoene synthase is devoted to abiotic stress-induced abscisic acid formation in rice and defines functional diversification of phytoene synthase genes. Plant Physiol. 147, 367-380. doi: 10.1104/pp.108.117028

Whelan, S., and Goldman, N. (2001). A general empirical model of protein evolution derived from multiple protein families using a maximum-likelihood approach. Mol. Biol. Evol. 18, 691-699. doi: 10.1093/oxfordjournals.molbev. a003851

Xin, H., Zhu, W., Wang, L., Xiang, Y., Fang, L., Li, J., et al. (2013). Genome wide transcriptional profile analysis of Vitis amurensis and Vitis vinifera in response to cold stress. PLoS One 8:e58740. doi: 10.1371/journal.pone.0058740

Yamaguchi-Shinozaki, K., and Shinozaki, K. (2006). Transcriptional regulatory networks in cellular responses and tolerance to dehydration and cold stresses. Annu. Rev. Plant Biol. 57, 781-803. doi: 10.1146/annurev.arplant.57.032905. 105444

Zheng, C., Halaly, T., Acheampong, A. K., Takebayashi, Y., Jikumaru, Y., Kamiya, Y., et al. (2015). Abscisic acid (ABA) regulates grape bud dormancy, and dormancy release stimuli may act through modification of ABA metabolism. J. Exp. Bot. 66, 1527-1542. doi: 10.1093/jxb/eru519

Conflict of Interest: The authors declare that the research was conducted in the absence of any commercial or financial relationships that could be construed as a potential conflict of interest.

Publisher's Note: All claims expressed in this article are solely those of the authors and do not necessarily represent those of their affiliated organizations, or those of the publisher, the editors and the reviewers. Any product that may be evaluated in this article, or claim that may be made by its manufacturer, is not guaranteed or endorsed by the publisher.

Copyright (c) 2022 Noronha, Silva, Silva, Frusciante, Diretto and Gerós. This is an open-access article distributed under the terms of the Creative Commons Attribution License (CC BY). The use, distribution or reproduction in other forums is permitted, provided the original author(s) and the copyright owner(s) are credited and that the original publication in this journal is cited, in accordance with accepted academic practice. No use, distribution or reproduction is permitted which does not comply with these terms 